Electronic Supporting Information (ESI) for

\title{
Self-Assembling Poly(Dioxaborole)s as Blue-Emissive Materials
}

\author{
Weijun Niu, Mark D. Smith and John J. Lavigne* \\ Department of Chemistry and Biochemistry, University of South \\ Carolina, Columbia, South Carolina 29208; \\ E-mail:lavigne@mail.chem.sc.edu
}

Contents:

(1) Synthesis and characterization of polymer 1

(2) Synthesis and characterization of model compound 2

(3) Gel Permeation Chromatography (GPC) methods

(4) Solid ${ }^{11} B$ NMR spectra of 1 and 2

(5) Single crystal X-ray structure of 2

(6) Powder XRD analysis of 1 and 3

(7) Calculated polarizabilities for a series of non-conjugated and conjugated linear oligomers

(8) Calculated electronic spectra for oligo(borole)s of increasing length

(9) Absorbance spectra of the di-boronic acid starting material, non-conjugated neopentyl glycol di-ester, 2 and 3 :

\section{Materials}

Chemicals for the synthesis of the polymer 1 were purchased from Acros and Aldrich and were used without further purification. All solvents were obtained from solvent purification systems from Innovative Technologies.

\section{Instrumentation}

Solution phase ${ }^{1} \mathrm{H}$ NMR spectra were collected on a Bruker $300 \mathrm{MHz}$ spectrometer. Solid-state

${ }^{11}$ B NMR spectra were collected on a Varian Inova $500 \mathrm{MHz}$ spectrometer with a Doty $4 \mathrm{~mm}$ XC-MAS probe. Absorbance studies were performed using a Beckman Coulter 640 DU 
spectrophotometer and quartz cuvets from Starna. Powder X-ray diffraction data were collected on a Rigaku DMax 2200 using $\mathrm{Cu} \mathrm{K} \alpha$ radiation.

\section{Synthesis}

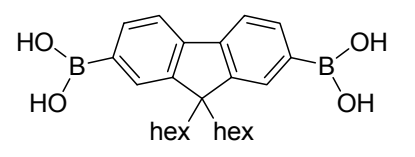

3

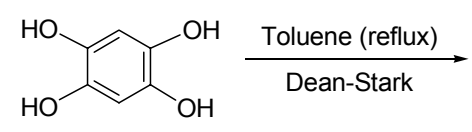

4

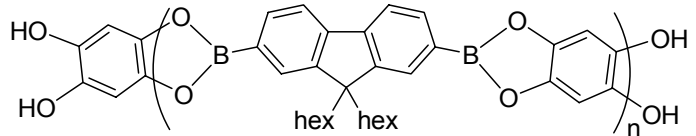

1

(1) Synthesis of 1: To a mixture of $0.1352 \mathrm{~g}$ (0.3202 mmol) of 9,9-dihexylfluorene-2,7diboronic acid and $0.1352 \mathrm{~g}(0.3220 \mathrm{mmol})$ of freshly-prepared 1,2,4,5-tetrahydroxybenzene in a flask fitted with a Dean-Stark trap, $50 \mathrm{ml}$ of distilled THF was added. Under an argon atmosphere, this resulting solution was refluxed for 30 minutes to yield a clear light yellowish solution which was then cooled to room temperature. Solvent THF was then removed under reduced pressure to yield a solid which is washed by distilled $\mathrm{CH}_{3} \mathrm{CN}$ to yield a powder product (0.1437 g, 91\%). ${ }^{1} \mathrm{H}$ NMR (300 MHz, DMSO- $\left.d_{6}, \delta\right): 7.80-7.72$ (dd, 4H, Ar H), 7.84 (s, 2H, Ar H), 6.20 (s, 2H, Ar H), 2.02-1.83 (br t, 4H, $\alpha$-methylene protons from the two hexyl chains), 1.12-0.91 (m, 12H), $0.72(\mathrm{t}, 6 \mathrm{H}), 0.55-0.43(\mathrm{~m}, 4 \mathrm{H})$; Solid ${ }^{11} \mathrm{~B}$ NMR (160.49 MHz, $\mathrm{BF}_{3} \bullet \mathrm{Et}_{2} \mathrm{O}$ at $0 \mathrm{ppm}$ as the external reference and boric acid as the second reference at 19.3 ppm): 31-35 ppm. 
${ }^{1} \mathrm{H}$ NMR of polymer $\mathbf{1}$

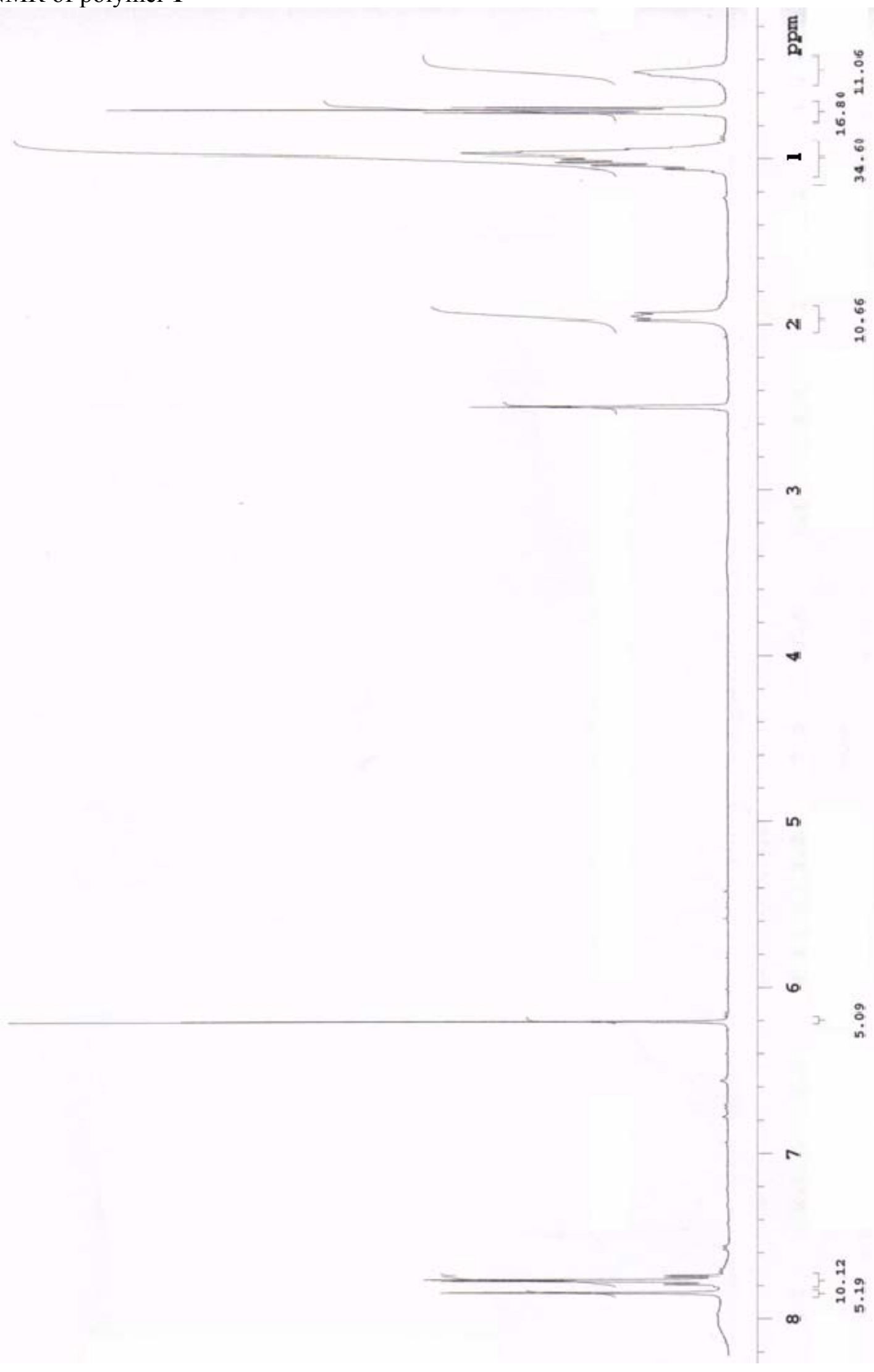



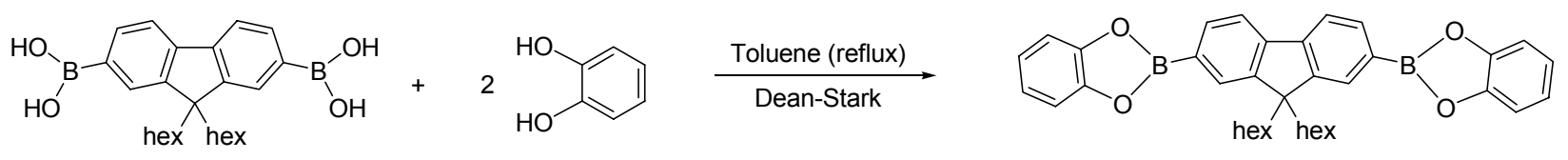

2

(2) Synthesis of 2: To a mixture of $0.3623 \mathrm{~g}(0.8582 \mathrm{mmol})$ of 9,9-dihexylfluorene-2,7-diboronic acid and $0.1890 \mathrm{~g}(1.7165 \mathrm{mmol})$ of catechol in a flask fitted with a Dean-Stark trap, $55 \mathrm{ml}$ of distilled toluene was added. Under Ar protection, this resulting solution was refluxed for 18 hours to yield a clear solution which is then cooled to room temperature. Solvent toluene in this solution was then removed under reduced pressure to form a white crystalline solid $(0.4789 \mathrm{~g})$. ${ }^{1} \mathrm{H} \mathrm{NMR}$ in $\mathrm{CDCl}_{3}: 8.11$ (dd, 2H, $\left.J=9.9,1.1 \mathrm{~Hz}\right), 8.09$ (s, 2H), $7.90(\mathrm{dd}, 2 \mathrm{H}, J=7.5,0.6 \mathrm{~Hz})$, $7.36\left(4 \mathrm{H}, \mathrm{AA}^{\prime}\right.$ of $\left.\mathrm{AA}^{\prime} \mathrm{BB}^{\prime}\right), 7.15\left(4 \mathrm{H}, \mathrm{BB}^{\prime}\right.$ of $\left.\mathrm{AA}^{\prime} \mathrm{BB}^{\prime}\right), 2.17-2.06(\mathrm{~m}, 4 \mathrm{H}, \alpha-$ methylene protons from the two hexyl groups), 1.14-0.93 $(\mathrm{m}, 12 \mathrm{H}), 0.73(\mathrm{t}, 6 \mathrm{H}$, six methyl protons from the two hexyl groups, $J=6.9 \mathrm{~Hz}), 0.68-0.52(\mathrm{~m}, 4 \mathrm{H}) ;{ }^{11} \mathrm{~B} \mathrm{NMR}\left(160.49 \mathrm{MHz}, \mathrm{CDCl}_{3}, \mathrm{BF}_{3} \bullet \mathrm{Et}_{2} \mathrm{O}\right.$ at 0 ppm as the external reference): $30 \mathrm{ppm}$. Solid ${ }^{11} \mathrm{~B}$ NMR $\left(160.49 \mathrm{MHz}, \mathrm{BF}_{3} \bullet \mathrm{Et}_{2} \mathrm{O}\right.$ at $0 \mathrm{ppm}$ as the external reference and boric acid as the second reference at $19.3 \mathrm{ppm}$ ): $28 \mathrm{ppm}$. MS calcd for $\mathrm{C}_{37} \mathrm{H}_{40} \mathrm{~B}_{2} \mathrm{O}_{4}:$ 570.3125; found (Direct-probe): $m / z$ 570.3141. Crystals for X-ray analysis were obtained by the slow evaporation of a $\mathrm{CH}_{2} \mathrm{Cl}_{2} /$ hexane solution of $\mathbf{2}$. 
(3) Gel Permeation Chromatography (GPC). Analyses were performed at room temperature with chloroform as the eluent, at a flow rate of $1.0 \mathrm{~mL} / \mathrm{min}$, using two Polymer Laboratories technology PLgel 5 $\mu \mathrm{m}$ MIXED-D columns connected in series. The detector used is a SPDM10 A VP Shimadzu Diode Array Detector. Calibration was performed using polystyrene standards (Polymer Laboratories for molecular weights, MW, 299 400, 143 400, 66 350, 38 100, $19880,9920,4920,2360,1260$ and 580).

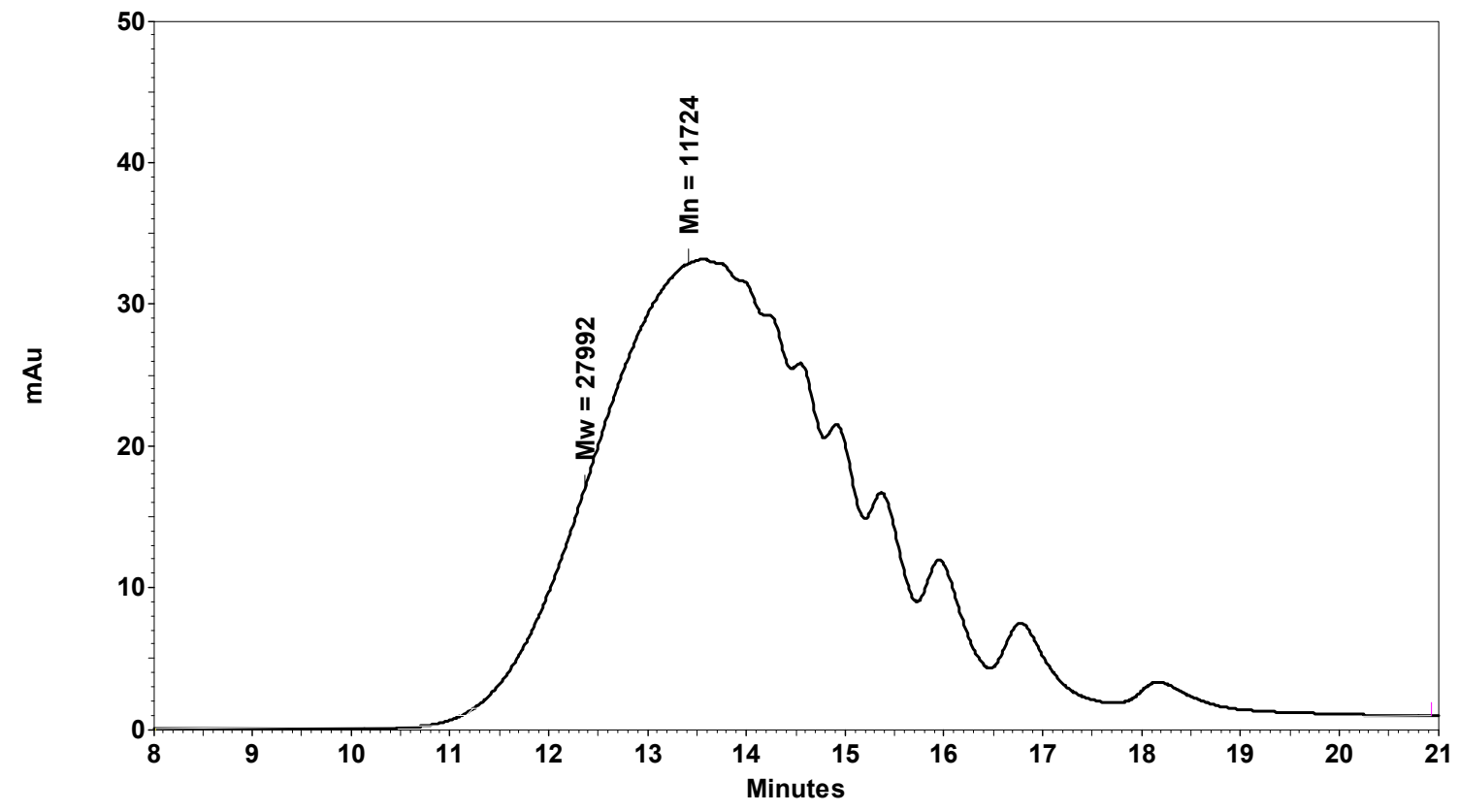

Figure S1. Typical GPC trace for a 1:10 acid:diol polymer: $M_{w} \approx 28,000 ; M_{w} / M_{n}=2.4$. 
(4) Solid ${ }^{11} B$ NMR spectra of $\mathbf{1}$ and 2: Solid ${ }^{11}$ B NMR were collected on a Varian Inova 500 $\mathrm{MHz}$ spectrometer with a Doty $4 \mathrm{~mm}$ XC-MAS probe operating at160.49 $\mathrm{MHz}$, using $\mathrm{BF}_{3} \bullet \mathrm{Et}_{2} \mathrm{O}$ at $0 \mathrm{ppm}$ as the external reference and boric acid as the second reference at $19.3 \mathrm{ppm}$.

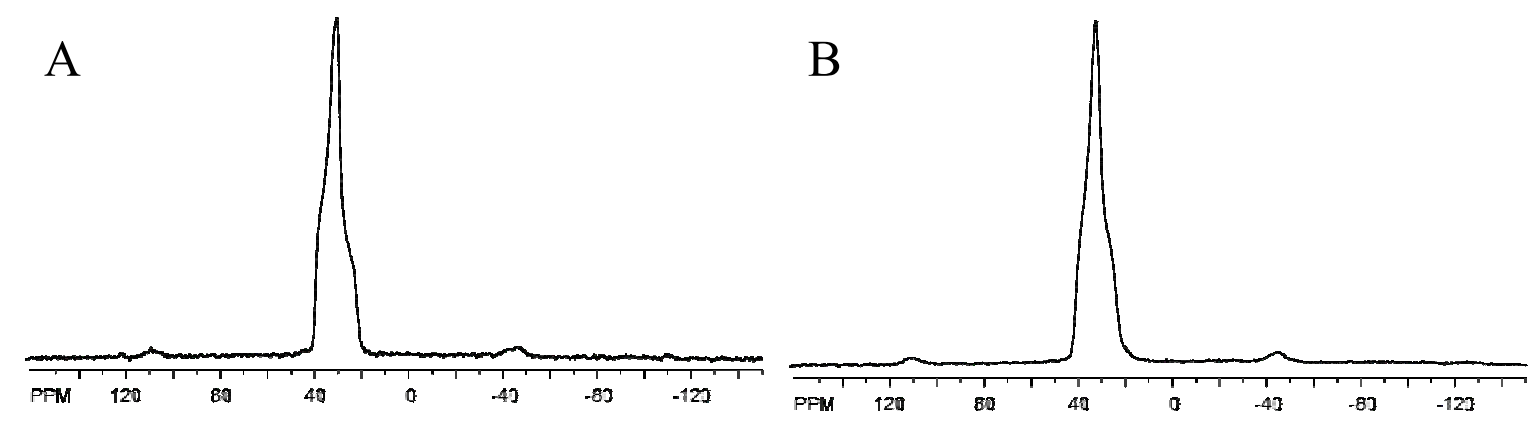

Figure S2. Solid ${ }^{11}$ B NMR of model compound 2 (A) and polymer 1 (B). 
(5) Single crystal X-ray structure of 2: X-ray intensity data from a colorless parallelipiped were measured at $150(2) \mathrm{K}$ on a Bruker SMART APEX CCD-based diffractometer (Mo K $\alpha$ radiation, $\lambda=0.71073 \AA$ ). ${ }^{1} \quad$ Raw data frame integration and $\mathrm{Lp}$ corrections were performed with SAINT $+{ }^{1}$ Final unit cell parameters were determined by leastsquares refinement of 6682 reflections with $\mathrm{I}>5(\sigma) \mathrm{I}$ from the data set. Analysis of the data showed negligible crystal decay during collection. The data were not corrected for absorption. Direct methods structure solution, difference Fourier calculations and full-matrix least-squares refinement against $\mathrm{F}^{2}$ were performed with SHELXTL. ${ }^{2}$

Systematic absences in the reflection data along with intensity statistics indicated the space group P2/n, which was eventually confirmed. The asymmetric unit consists of half of the molecule located on a two-fold rotational axis. Non-hydrogen atoms were refined with anisotropic displacement parameters; hydrogen atoms were placed in geometrically idealized positions and included as riding atoms.
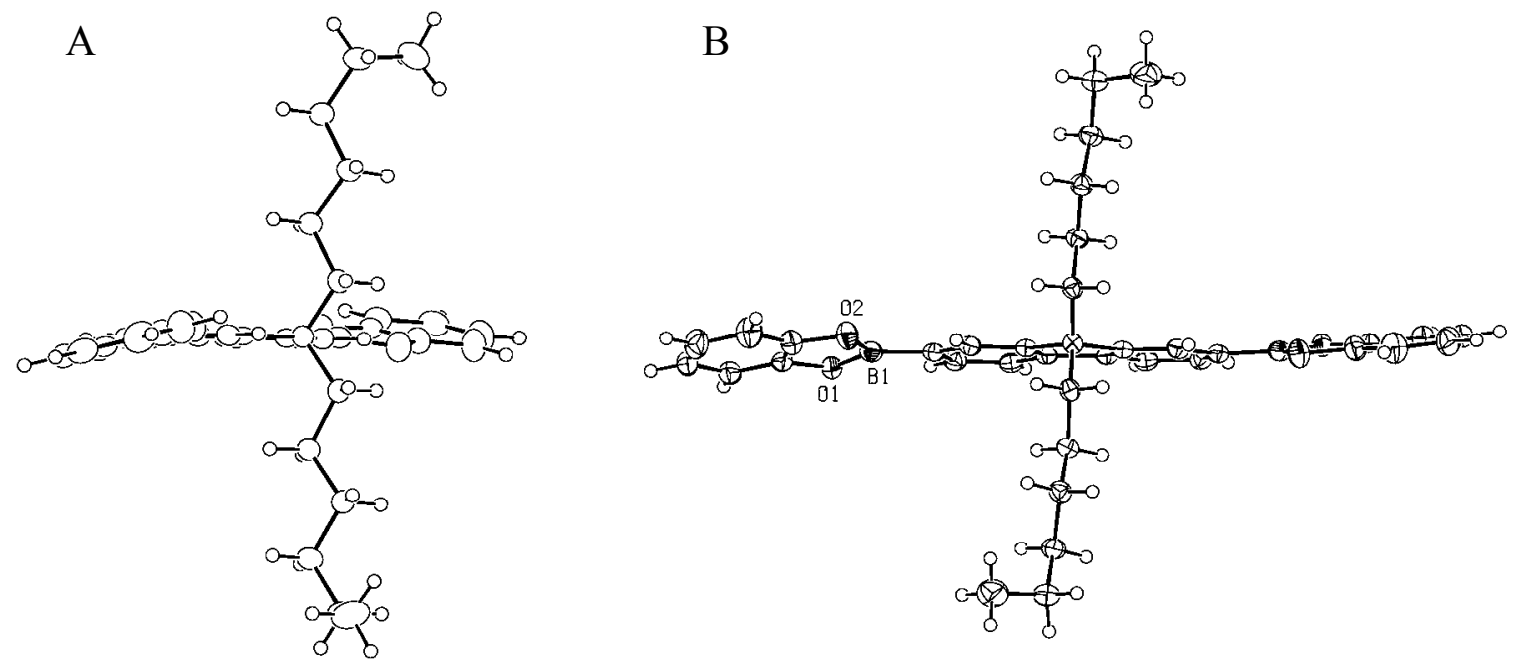

Figure S3. Edge-on views of the structure of 2 along the $\mathrm{C} 2$ axis, showing planarity of the fluorine-borole-phenyl system. Displacement ellipsoids drawn at the $50 \%$ probability level. 
Table S1. Crystal data and structure refinement for 2.

Empirical formula

Formula weight

Temperature

Wavelength

Crystal system

Space group

Unit cell dimensions

Volume

Z

Density (calculated)

Absorption coefficient

$\mathrm{F}(000)$

Crystal size

Theta range for data collection

Index ranges

Reflections collected

Independent reflections

Completeness to theta $=25.12^{\circ}$

Absorption correction

Refinement method

Data / restraints / parameters

Goodness-of-fit on $\mathrm{F}^{2}$

Final $\mathrm{R}$ indices $[\mathrm{I}>2 \operatorname{sigma}(\mathrm{I})]$

$\mathrm{R}$ indices (all data)

Extinction coefficient

Largest diff. peak and hole
C37 H40 B2 O4

570.31

150(2) K

$0.71073 \AA$

Monoclinic

$\mathrm{P} 2 / \mathrm{n}$

$\mathrm{a}=10.2014(6) \AA \quad \alpha=90^{\circ}$.

$\mathrm{b}=10.9644(6) \AA$

$\beta=92.5600(10)^{\circ}$.

$\mathrm{c}=13.9002(8) \AA$

$\gamma=90^{\circ}$.
2

$1.219 \mathrm{Mg} / \mathrm{m}^{3}$

$0.076 \mathrm{~mm}^{-1}$

608

$0.52 \times 0.26 \times 0.08 \mathrm{~mm}^{3}$

1.86 to $25.12^{\circ}$.

$-12<=\mathrm{h}<=12,-13<=\mathrm{k}<=12,-16<=\mathrm{l}<=16$

12221

$2754[\mathrm{R}(\mathrm{int})=0.0459]$

$99.4 \%$

None

Full-matrix least-squares on $\mathrm{F}^{2}$

2754 / 0 / 197

1.079

$\mathrm{R} 1=0.0453, \mathrm{wR} 2=0.1008$

$\mathrm{R} 1=0.0533, \mathrm{wR} 2=0.1050$

0.0037(10)

0.235 and -0.167 e. $\AA^{-3}$ 
(6) Powder XRD analysis of 1 and 3: Powder X-ray diffraction data were collected on a Rigaku DMax 2200 using $\mathrm{Cu} \mathrm{K} \alpha$ radiation. The sample was mounted in a deep well glass slide. Data were collected from $2-70^{\circ} 2 \theta$ with steps of $0.02^{\circ}$ with a count time of $12 \mathrm{~s}$ per step. There were no observable diffraction lines beyond $50^{\circ} 2 \theta$ so this data was not shown.

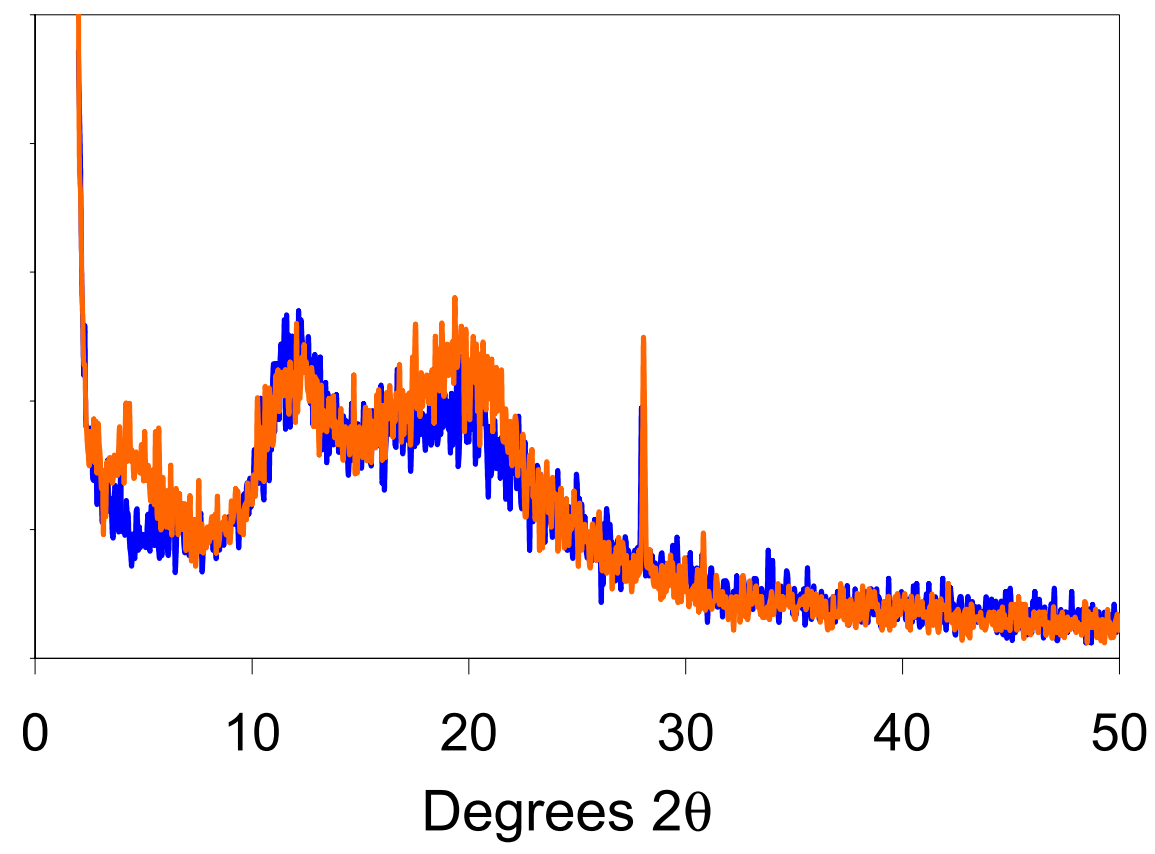

Figure S4. Powder XRD patterns for polymers $\mathbf{1}$ (orange) and $\mathbf{3}$ (blue), lacking any solid state ordering, indicative of amorphous materials. 
(7) Table S2. Calculated polarizabilities for a series of non-conjugated and conjugated linear polymers.

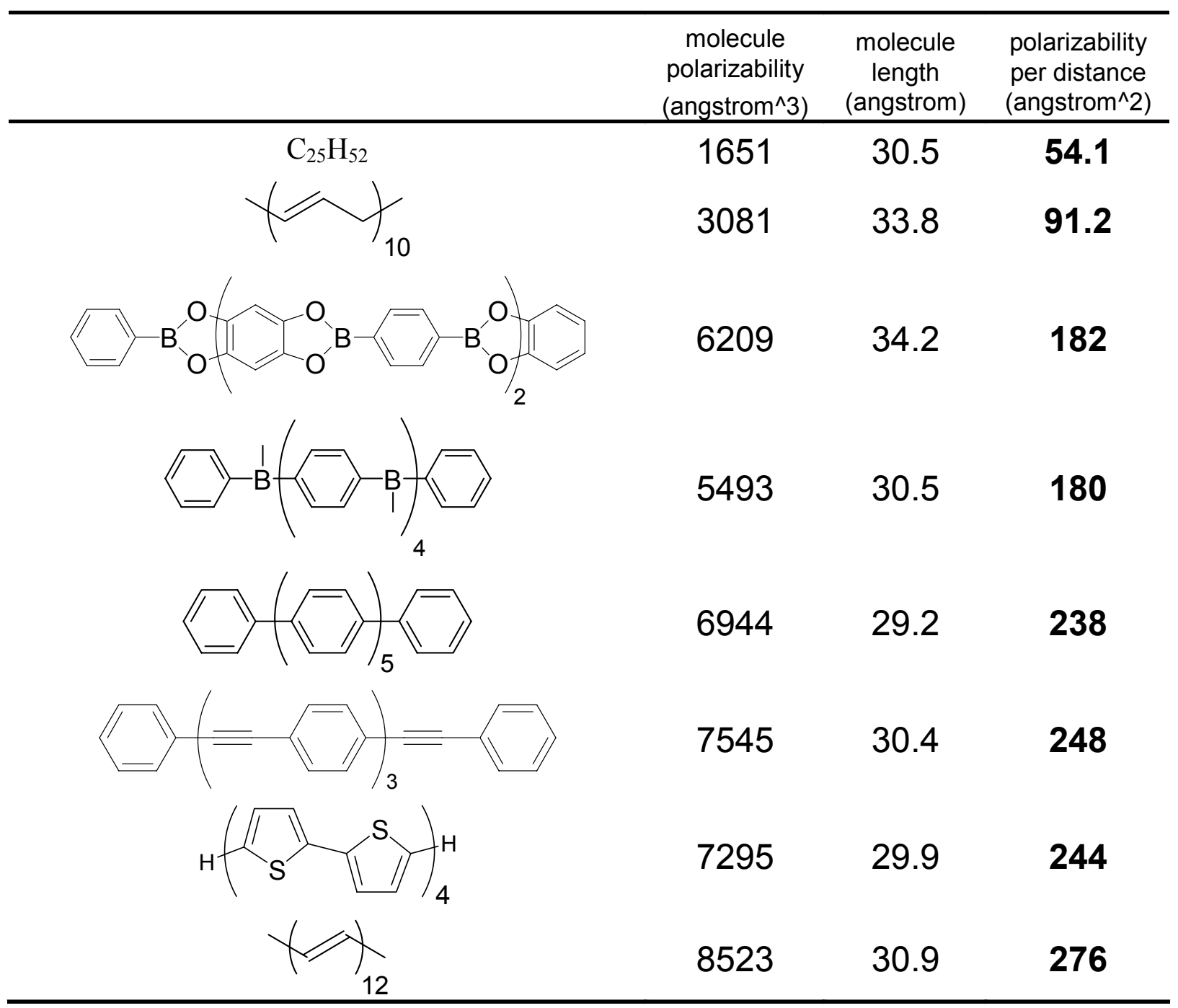

Geometry optimization based on molecular mechanics was carried out using the AMBER force field ${ }^{3}$ in Chem3D. ${ }^{4}$ Oligomers were forced to be planar prior to optimization and the routine biased to maintain planarity. For the optimized structures, polarizabilities were calculated using the AM1 routine ${ }^{5}$ in $C S M O P A C P R O .^{6}$ Polarizability comparisons were along the long axis of each oligomer. Lengths were determined by the distance measured in Chem $3 D$ from the terminal heavy atoms of each chain. 
(8) Table S3. Calculated electronic spectra for oligo(borole)s of increasing length

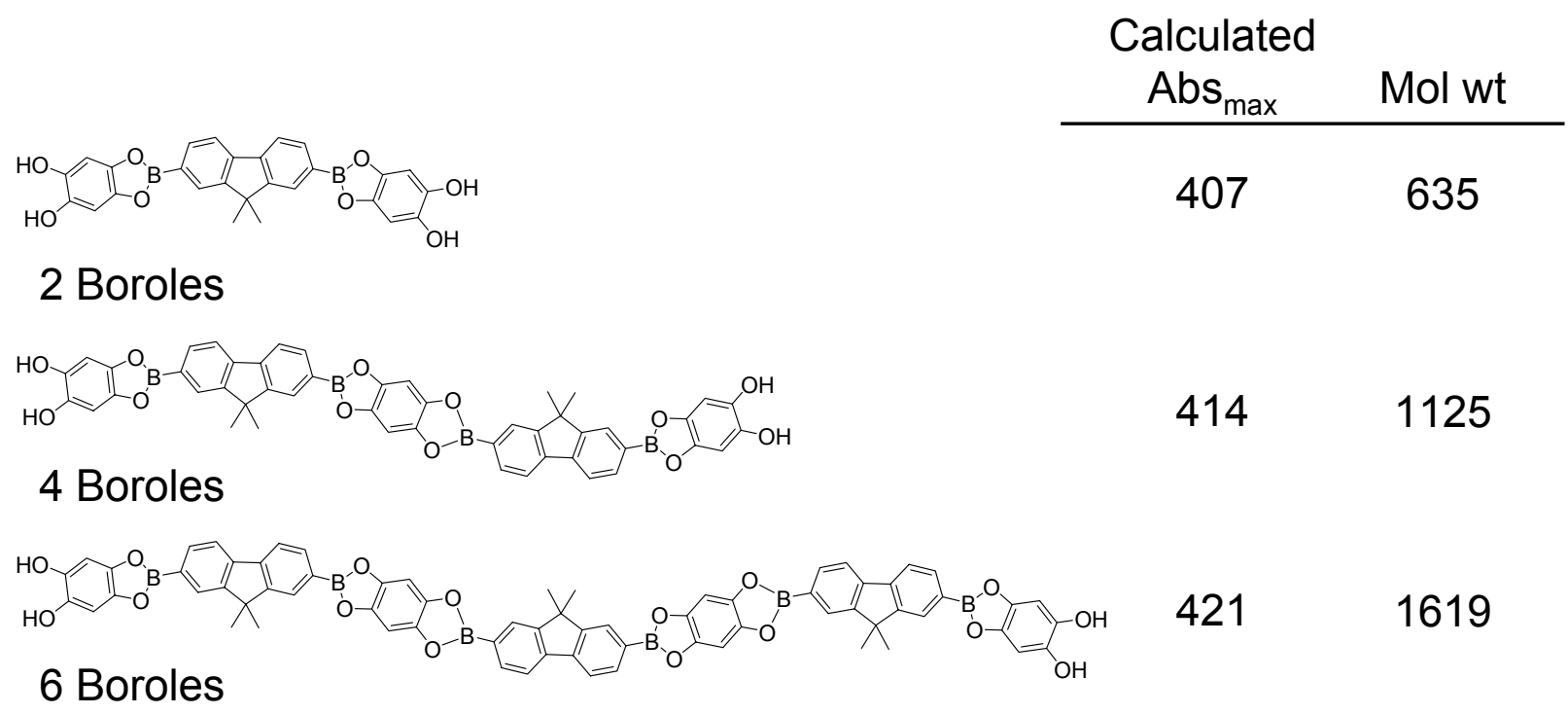

Geometry optimization based on molecular mechanics was carried out at $10 \mathrm{~K}$ using the AMBER force field ${ }^{3}$ in HyperChem. ${ }^{7}$ Oligomers were forced to be planar prior to optimization and the routine biased to maintain planarity. For the optimized structures, electronic spectra were generated using the routine $\mathrm{ZINDO} / 1$ following a singly excited configuration interaction (CI) calculation with the semi-empirical method (energy criterion $=10 \mathrm{eV}$ ). The numbers of occupied and unoccupied orbitals set in the single point CI calculations were both set equal to ten. The hexyl substituents on the fluorene unit were truncated to methyl groups to reduce the cost of the calculation. 
(9) Absorbance spectra of the di-boronic acid starting material, non-conjugated neopentyl glycol di-ester, 2 and 3 :
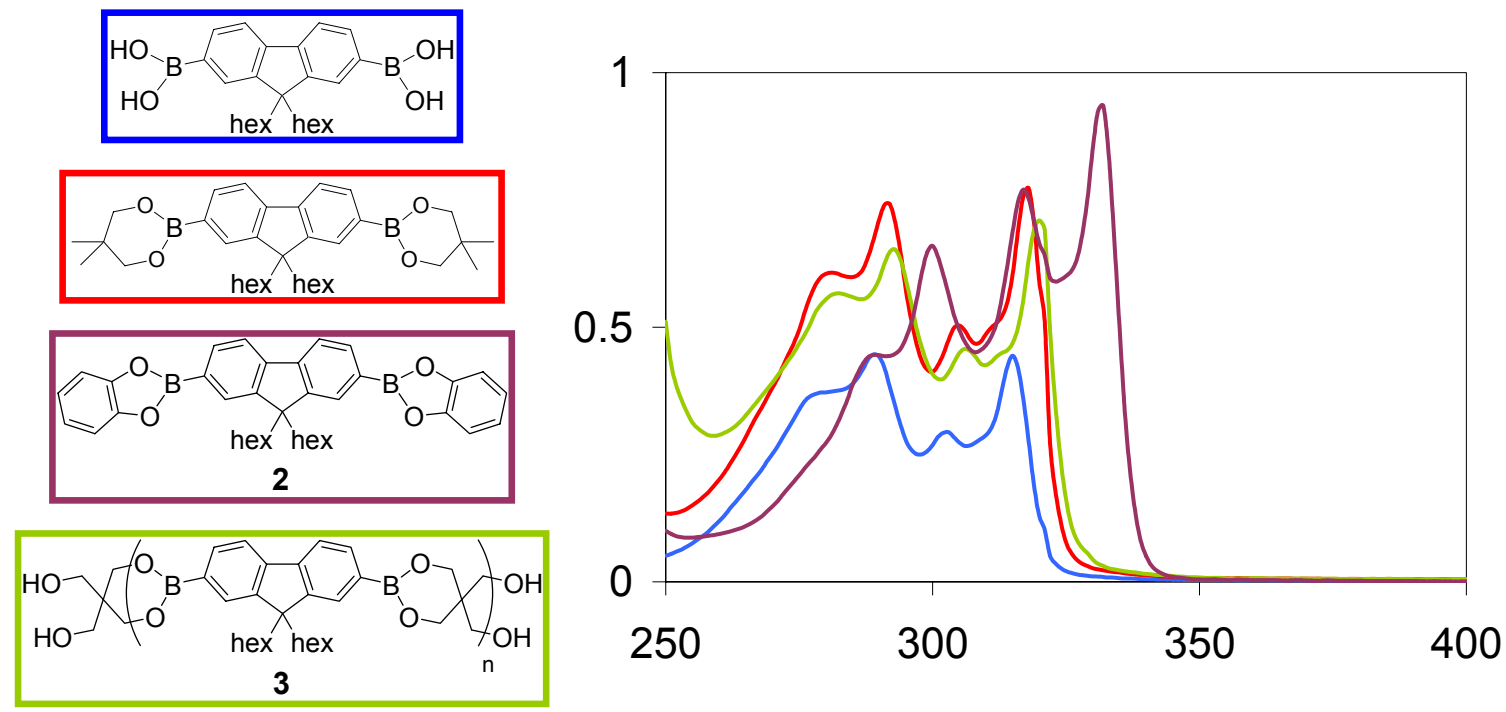

Figure S5. Absorption spectra for the di-boronic acid starting material (blue), non-conjugated neopentyl glycol di-ester (red), conjugated model compound 2 (purple), and non-conjugated polymer 3 all at $1 \times 10^{-5} \mathrm{M}$ (polymers based on repeat concentration).

1 SMART Version 5.625 and SAINT+ Version 6.22. Bruker Analytical X-ray Systems, Inc.: Madison, Wisconsin, 2001.

2 Sheldrick, G. M. SHELXTL Version 6.1; Bruker Analytical X-ray Systems, Inc.: Madison, Wisconsin, 2000.

3 Cornell, W. D.; Cieplak, P.; Bayly, C. I.; Gould, I. R.; Merz, K. M.; Ferguson, D. M.; Spellmeyer, D. C.; Fox, T.; Caldwell, J. W.; Kollman, P. A. J. Am. Chem. Soc. 1995, 117, 5179-5197.

4 Chem3D, CambridgeSoft Corp.: Cambridge, MA., 2000.

5 Dewar, M. J. S.; Zoebisch, E. G.; Healy, E. F.; Stewart J. J. P., J. Am. Chem. Soc. 1985, 107, 3902-3909

6 CS MOPAC Pro-MOPAC 2000, Version 6.0; CambridgeSoft Corp.: Cambridge, MA., 2000

7 HyperChem, version 7.0; HyperCube Inc.: Gainesville, FL., 2002. 